\title{
Mathematical models and methods of prolongation of operating lifetimes for expensive objects
}

\author{
Vladimir Trukhanov ${ }^{1, *}$, Mikhail Kukhtik ${ }^{1}$, and Natal'ya Fyodorova ${ }^{1}$ \\ ${ }^{1}$ Volgograd State Technical University, Department of Production Process Automation, 400005 \\ Volgograd, Russia
}

\begin{abstract}
The article is devoted to the relevant issue of prolongation of operating lifetimes for expensive objects. The methods of prolongation of operating lifetimes for complex technical systems have been described. In particular, the mathematical model of prolongation of operating lifetimes by the calculation and analytical method, which is based on normal distribution law of actual load and durability, has been represented. The experimental method, which is based on analysis of actual technical state of element base and material, has been described. The probabilistic method of calculation of reliability function during prolonged operating lifetime taking into account actual technical state of element base has been represented.
\end{abstract}

\section{Introduction}

The final stage of the lifecycle of expensive objects is prolongation of operating lifetimes with acceptable level of reliability and output technical characteristics [1-5].

Hence and with regard to large cost of research object, the issue of ensuring of preset level of reliability and other operational characteristics of complex technical systems at prolonged operating lifetime becomes relevant. The issue of prediction of technical life of complex technical system is relevant and is based on actual technical state of its components [6-8]. This issue happens to solve at prolonged operating lifetime, for example, by replacement of mechanisms, assemblies, devices and apparatus, which have exceeded assigned life, and in the case of prolongation of operating lifetimes over guarantee ones as well [9-11].

The known method of prolongation of operating lifetimes is based on normative and technical documentation by only replacement of constituent elements and components, which have exceeded established life $[12,13]$. The proposed approach consists in so as to keep established in normative documentation technical and operational characteristics at acceptable level at prolonged operating lifetime including quantitative reliability indices.

\footnotetext{
*Corresponding author: trukhanov1939@mail.ru
} 
Thus, newness of new approach specifies the existent method of prolongation of operating lifetimes by addition of calculation and analytical, experimental and probabilistic methods [14].

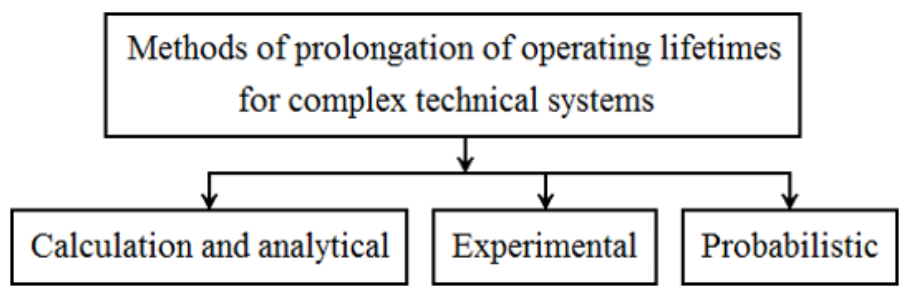

Fig. 1. Methods of prolongation of operating lifetimes for complex technical systems.

\section{The calculation and analytical method}

The calculation and analytical method is based on theoretical statements and calculations of life and endurance prolongation on criteria of durability, wear resistance, corrosion stability and other criteria on actual technical state of object at the moment of prolongation of operating lifetimes. Quantile of normal distribution function is calculated on estimated value of margin and variation coefficients of metal constructions and mechanical units. Nonfailure operation probability [14] is determined on quantile by the formula

$$
P=\Phi\left(u_{p}\right)
$$

where $u_{p}$ is the quantile of normal distribution function, is chosen from the tables [12, $15,16]$.

$$
u_{p}=\frac{n-1}{\sqrt{\left(n v_{1}\right)^{2}+v_{2}^{2}}},
$$

where $n$ is the margin coefficient of durability, wear resistance, corrosion stability etc.;

$v_{1}$ is the variation coefficient of durability, wear resistance, corrosion stability etc.;

$v_{2}$ is the variation coefficient of actual load, humidity, temperature etc.

$$
v_{1}=\frac{\sigma_{1}}{m_{1}} ; \quad v_{2}=\frac{\sigma_{2}}{m_{2}}
$$

$m_{1}, \quad \sigma_{1}$ are the mathematical expectation of margin of durability, wear resistance, corrosion stability etc. and the standard deviation;

$m_{2}, \sigma_{2}$ are the mathematical expectation of load, humidity, temperature etc. and the standard deviation.

Let us represent the analytical expressions of quantiles for determining of nonfailure operation probability as examples [14].

Design formula for criterion of wear of attrition faces looks in the following way:

$$
u_{p}=\frac{n-1}{\sqrt{n^{2} v_{\Delta}^{2}+v_{J}^{2}}},
$$


where $n$ is the margin coefficient on wear, $n=\frac{\Delta}{J v t}$;

$J$ is the mean value of wear intensity;

$v$ is the speed of relative movement of attrition faces;

$t$ is the performance time of attrition faces;

$v_{\Delta}$ is the variation coefficient of part magnitude, $v_{\Delta}=\frac{\sigma_{h}}{\Delta}$;

$\sigma_{h}$ is the standard deviation of initial magnitude;

$\Delta=h_{\text {init }}-h_{\max }$, when magnitude decreases;

$\Delta=h_{\max }-h_{\text {init }}$, when magnitude increases;

$h_{\text {init }}$ is the initial value of magnitude;

$h_{\max }$ is the maximum permissible value of magnitude under wear;

$v_{J}$ is the variation coefficient of wear intensity, $v_{J}=\frac{\sigma_{J}}{J}$;

$\sigma_{J}$ is the standard deviation of wear intensity.

Design formula for criterion of part durability looks in the following way:

$$
u_{p}=\frac{n-1}{\sqrt{n^{2} v_{t}^{2}+v_{p}^{2}}},
$$

where $n$ is the coefficient of durability margin, depending on mean values of yield point $\sigma_{t}$ and stress $\sigma_{e q}, \quad n=\frac{\sigma_{t}}{\sigma_{e q}}$;

$v_{t}$ is the variation coefficient of yield point;

$v_{p}$ is the variation coefficient of pressure.

Calculations at the stage of prolongation of operating lifetimes must be carried out on actual technical state of elements, units and assemblies at the moment of prolongation.

This method is used both in design calculation of reliability and when operating lifetimes of complex mechanical, hydromechanical, hydraulic systems and devices are prolonged.

In the case of disconfirmation of sufficient margins elements and units are subjected to constructive reprocessings at the design stage or to mandatory replacement in provided terms according to normative and technical documentation at the operation stage. Under conditions of prolongation of operating lifetimes necessity of replacement of materials and constituent elements by more durable ones is determined with a view to ensure preset output technical and operational characteristics and preset reliability level as well.

\section{The experimental method}

The experimental method is based on analysis of actual technical state of materials, elements, assemblies and product integrally after expiration of guarantee or established operating lifetime of complex technical system. Developer of given system chooses no less than two systems from operational locations, which have exhausted guarantee or established lifetime, where they have been operated. Functioning testing is carried out on chosen systems in amount of double or triple guarantee or established life. During the functioning process all output technical and operational characteristics are measured and 
after functioning reliability level is estimated and compared with requirements of technical conditions. Then components are dismounted on chosen systems (assemblies, units, desks and other equipment) and are tested on functioning as part of desks with measurements of output technical parameters and recording of actual values of parameters in data sheet or logbook. After that assembly, unit or desk is subjected to dismounting and flaw detection of each element with measurements of geometric parameters and technical and operational parameters as well (for example, output current or voltage of electronic element, engine power, time of moving-out and retraction of jack etc.).

According to the results of estimation of actual technical state of elements and units, procedures, which are directed to increase of life both of individual elements, units, assemblies and product integrally, are developed. Procedures, which are directed to increase of life can have construction, technological and operational character.

Construction procedures are most often connected with replacement of less stable materials to external actions by more stable ones for different climatic zones. Thus, materials, which are more enduring to low temperatures, are used for systems, which perform under conditions of low temperatures (for example, metal constructions should be made from killed steels, low-temperature operating fluids should be used in units and mechanisms etc.). Materials, which are stable to thermites, are chosen for products, which perform under conditions of high temperatures and tropical climate, and clearance is increased in couplings of attrition faces, high-temperature operating fluids are used in units and mechanisms etc.

Procedures of technological character are directed to improvement of technological process in part of stableness increase of material surface coating to decrease of wear intensity, increase of time on corrosive influences and cavitation etc.

Procedures of operational character are directed to more precise definition of operational documentation in part of reduction of number of failures caused by violation of operating instruction. For example, when the most crucial operations of system functioning are executed, it is necessary to provide for particular signs of attention in operating instruction and put them directly at working place of operator, which carries out this performance, in the form of tablet.

According to the results of researches, all objects, which are in operation, are reprocessed on bulletins, and operational documentation is corrected taking into account prolongation of operating lifetimes in part of modification and more precise definition of maintenance supports and replacements of constituent elements and units on preset run or preset time. Consecution of carrying out of performances on prolongation of operating lifetimes is represented at fig. 2. 
The experimental method is based on carrying out of the following kinds of performances

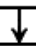

Functioning testing of two objects

in amount of double or triple guarantee life

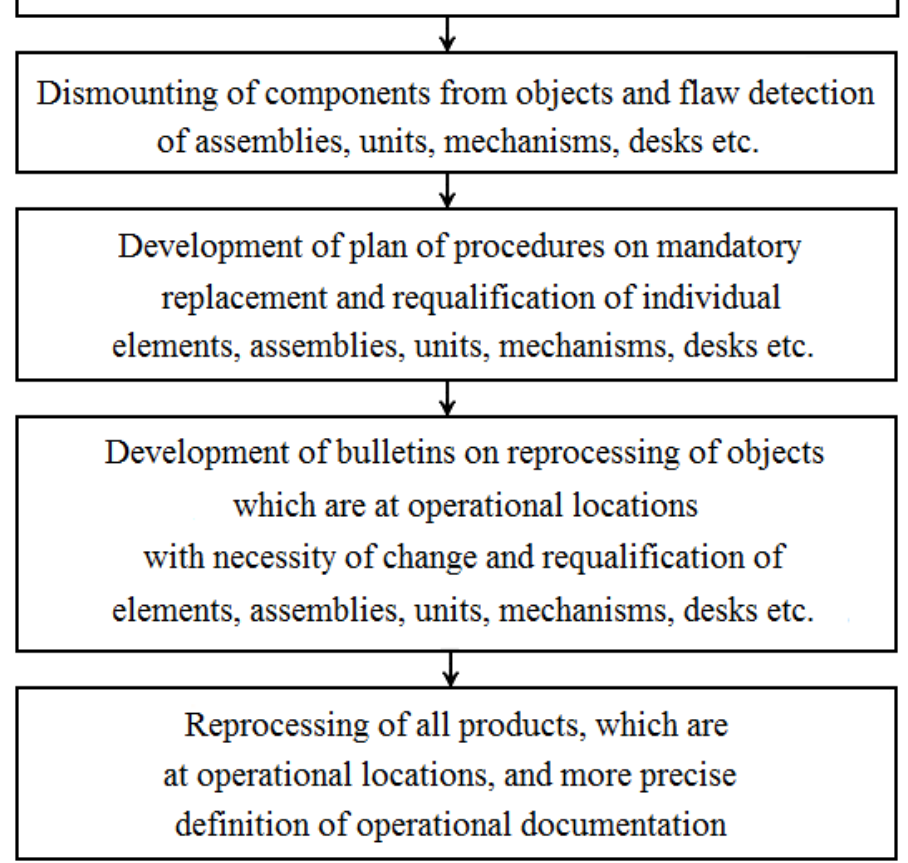

Fig. 2. Consecution of carrying out of performances on prolongation of operating lifetimes for complex technical systems.

\section{The probabilistic method of calculation of reliability function during prolonged operating lifetime taking into account actual technical state of element base}

The probabilistic method is based on probability calculations of reliability indices, which are established in technical conditions. Reliability calculations are carried out on durability margins and their deviations for metal constructions, mechanical units, attrition faces etc. When operating lifetimes of communications electronics equipment are prolonged, different kinds of redundancy are considered and required terms of requalification or mandatory replacement of appropriate elements and units are established in operating documentation as well.

At probability calculations it is recommended to use methodology of calculation taking into account control actions, which is considered in parts 5.3 and 5.4 [14].

Reliability function at prolonged operating lifetime taking into account actual technical state of element base is determined by the expression

$$
G(t, \lambda, \alpha, \beta)=P(t, \lambda) R(t, \alpha, \beta)=\exp (-\lambda t) \exp \left(-\alpha t^{\beta}\right),
$$


where $P(t, \lambda)$ is the one-parameter reliability function, which takes into account random failures depending on actual technical state of element base;

$R(t, \alpha, \beta)$ is the two-parameter reliability function, which takes into account nonrandom failures depending on actual technical state of element base.

In the model of calculation of reliability function taking into account control actions matrix of parameters $\mathbf{B}$ ' is formed on actual technical state of element base at the moment of prolongation of operating lifetime

$$
\mathbf{B}^{\prime}=\left[\begin{array}{cccc}
b_{11}^{\prime} & b_{11}^{\prime} & \cdots & b_{1 m}^{\prime} \\
b_{21}^{\prime} & b_{21}^{\prime} & \cdots & b_{2 m}^{\prime} \\
\cdots & \cdots & \cdots & \cdots \\
b_{n 1}^{\prime} & b_{n 1}^{\prime} & \cdots & b_{n m}^{\prime}
\end{array}\right],
$$

and shape parameter takes on a value $\beta=2 \div 4$, when reliability function $R(t, \alpha, \beta)$ is calculated.

When reliability of metal constructions and mechanical units is calculated at period of prolonged operating lifetime, margins of durability, wear resistance, fatigue etc. are recounted depending on actual technical state of constructive parameters of elements, units, mechanisms etc. by the formula

$$
P=\Phi\left(\frac{n^{\prime}-1}{\sqrt{\left(n^{\prime} v_{1}^{\prime}\right)^{2}+\left(v_{2}^{\prime}\right)^{2}}}\right),
$$

where $n^{\prime}=\frac{m_{1}^{\prime}}{m_{2}^{\prime}}$ is the coefficient of durability margin of element, unit, mechanism etc. on actual technical state at the moment of prolongation of operating lifetime;

$m_{1}^{\prime}, \quad \sigma_{1}^{\prime}$ are the mean value of durability and its standard deviation at the moment of prolongation of operating lifetime;

$m_{2}^{\prime}, \quad \sigma_{2}^{\prime}$ are the mean value of load and its standard deviation at the moment of prolongation of operating lifetime;

$v_{1}^{\prime}=\frac{\sigma_{1}^{\prime}}{m_{1}^{\prime}}$ is the coefficient of durability variation;

$v_{2}^{\prime}=\frac{\sigma_{2}^{\prime}}{m_{2}^{\prime}}$ is the coefficient of load variation;

$u_{p}=\frac{n^{\prime}-1}{\sqrt{\left(n^{\prime} v_{1}^{\prime}\right)^{2}+\left(v_{2}^{\prime}\right)^{2}}}$ is the quantile of normal distribution function, which corresponds to probability $P$, is chosen from table (appendix $1[14]$ ).

\section{Conclusions}

The methods of prolongation of operating lifetimes for complex technical systems have been considered. The calculation and analytical method of prolongation of operating lifetimes in terms of normal distribution law of load and durability has been represented. The experimental method of prolongation of operating lifetimes, which is based on analysis 
of actual technical state of material and element base, has been stated. The probabilistic method of calculation of reliability function during prolonged operating lifetime taking into account actual technical state of element base has been represented.

The considered methods have found a use at several enterprises of machine-building industry, for example, at «Federal research and production center «Titan-Barrikady» (Volgograd), «Plant no. 9» (Ekaterinburg) and «Manufacturing facility «Akhtuba» (Volgograd). The obtained scientific results have been used, when the monographs [14, 1719] have been published, and in the educational process of Volgograd state technical university.

The reported study was funded by RFBR according to the research project no. 17-01-00018.

\section{References}

1. K.C. Kapur, M. Pecht, Reliability Engineering (Wiley \& Sons, Inc., Hoboken, New Jersey, 2014)

2. A. Birolini, Reliability Engineering: Theory and Practice (Springer, New York, London, 2017)

3. Y.N. Nikolaev, Aspects of assessment of organizational and technical reliability and design of construction processes with target reliability level using computer-aided technologies, 2nd International Conference on Industrial Engineering, Applications and Manufacturing (ICIEAM), Chelyabinsk, Russia, 19-20 May, pp. 1-4 (2016)

4. E.N. Desyatirikova, L.V. Chernenkaya, V.E. Mager, Method of Calculating A Priori Reliability of Elements of Complex System, International Russian Automation Conference (RusAutoCon), Sochi, Russia, 9-16 Sept., pp. 1-4 (2018)

5. V.M. Trukhanov, M.P. Kukhtik, A technique of synthesizing control actions to ensure a preset level of reliability, Journal of Machinery Manufacture and Reliability, v. 5(1), pp. 43-53 (2019)

6. G.I. Chernyavskij, Control of operation of missile armament, (The Military Academy of Strategic Rocket Troops after Peter the Great, Moscow, 2009)

7. G.A. Berketov, A.A. Mikryukov, V.I. Shvej, Forecasting of the individual residual resource of the fixed capital when planning the enterprise modernization, Ekonomika, statistika i informatika, no. 4, pp. 58-62 (2008)

8. K.A. Kuznetsov, Methods, models, and means of increasing the efficiency of the estimation of the technical conditions and residual operation life of technical devices, International Journal of Sustainable Manufacturing, v. 43(6), pp. 497-502 (2014)

9. V.I. Dubrovin, V.A. Klimenko, Methods of extimation of residual life of products (review), Matematicheskie mashiny i sistemy, no. 4, pp. 162-168 (2010)

10. G.S. Sadyhov, V.P. Savchenko, O.V. Eliseeva, Basics of estimations of residual life of products, Vestnik MGTU im. N. E. Baumana. Seriya «Estestvennye nauki», no. S3, pp. 83-99 (2011)

11. A.S. Gusev, S.A. Starodubceva, V.I. Shcherbakov, Prediction of residual life based on the results of diagnosis of full-scale constructions and continuous monitoring of their technical condition, Izvestiya MGTU, v. 4(1(19)), pp. 100-104 (2014)

12. B. Willems, W. Dewulf, J.R. Duflou, A method to assess the lifetime prolongation capabilities of products, International Journal of Sustainable Manufacturing, v. 1(1-2), pp. 122-144 (2008) 
13. S.A. Davydov, Klimov O.Y., Krylov D.I., Makeev M.V., Tarasov P.A., Ramzin A.B., Yashnikov D.V., Estimation of possibility of prolongation of safe operating lifetime for automation system of technical device explotable at hazardous production facility, Problemy sovremennoj nauki i obrazovaniya, v. 2(44), pp. 85-92 (2016)

14. V.M. Trukhanov, New approach to securing of reliability of complex systems, (Izdatel'skij dom «Spektr», Moscow, 2010)

15. E.S. Ventstel', Probability theory, (Yusticiya, Moscow, 2018).

16. B.V. Gnedenko, Y.K. Belyaev, A.D. Solov'ev, Mathematical methods in reliability theory. Main reliability characteristics and their statistical analysis, (Editorial URSS, Moscow, 2019)

17. V.M. Trukhanov, A.M. Matveenko, Reliability of complex systems at all stages of the lifecycle, (Izdatel'skij dom «Spektr», Moscow, 2016)

18. V.M. Trukhanov, Reliability in technics, (Izdatel'skij dom «Spektr», Moscow, 2017)

19. V.M. Trukhanov, M.M. Sultanov, Reliability of power equipment of thermal-power plants, (Izdatel'skij dom «Spektr», Moscow, 2019) 